\title{
TEKNOLOGI PEMBELAJARAN MATEMATIKA PEMBUKTIAN TEOREMA PYTHAGORAS BERBASIS VISUAL
}

\author{
Muhammad Naufal Faris, Saida Ulfa, Henry Praherdhiono \\ Universitas Negeri Malang
}

\begin{abstract}
Article History
Received: April 16, 2019

Accepted:May 10, 2019

Published:June 30, 2019
\end{abstract}

\section{Keywords}

GeoGebra, Mathematics, Pythagorean Theorem, Discover, Proof

\begin{abstract}
Abstrak
Pythagoras merupakan seorang filsuf dan ahli matematika Yunani kuno. Salah satu kontribusi besar bagi sains dan matematika adalah Teorema Pythagoras. Teorema ini menyatakan bahwa kuadrat si si miring adalah sama dengan jumlah kuadrat dari kedua sisi lainnya. Teorema Pythagoras ditulis sebagai persamaan yang menghubungkan panjang sisi a, $\mathrm{b}$, dan $\mathrm{c}$, yang sering dikenal dengan bentuk umum persamaan $\boldsymbol{a}^{2}+\boldsymbol{b}^{2}=\boldsymbol{c}^{2}$. Bukti Teorema Pythagoras sangat bervariasi. Ada berbagai cara untuk membuktikan Teorema Pythagoras dengan skema pembuktian dari euclid bahkan di era digital dapat dibuktikan dengan menggunakan teknologi. Abad ke 21 penggunaan teknologi merupakan sebagai sumber pengembangan pembelajaran. Progam matematika GeoGebra merupakan sebuah perangkat lunak gratis dan open source yang mampu digunakan dalam pembelajaran. Pembelajaran matematika dapat dipelajari menggunakan GeoGebra seperti aljabar, geometri, kalkulus, dan statistik. GeoGebra juga merupakan perangkat lunak interaktif dalam proses pembelajaran. Artikel ini menyajikan ilustrasi visual bagaimana kita dapat menggunakan GeoGebra untuk pembelajaran dalam proses menemukan dan membuktikan Teorema Pythagoras.
\end{abstract}

\begin{abstract}
Pythagoras, one of the most famous ancient Greek philosophers and mathematician. One of the great contributions to science and mathematics was the Pythagorean Theorem. It states that the square of the hypotenuse is equal to the sum of the squares of the other two sides. The theorem Pythagoras be written as an equation relating the lengths sides $c, b$, and $a$, often known the "Pythagorean equation" $a^{2}+b^{2}=c^{2}$. The evidence of the Pythagorean theorem varies greatly. There are various ways the euclid to prove Pythagoras Theorem a simple and complex even in the digital era can use of technology. In the 21st century the use of technology as a source of learning development. In Mathematics GeoGebra is free software and open source. Mathematics learning can be studied like algebra, geometry, calculus, and statistics. GeoGebra is an interactive software for study mathematics. The paper presents illustrate how we can use GeoGebra to guide learners in the processes of discovering and Prove The Pythagorean Theorem.
\end{abstract}

Corresponding author :

Adress: J1.Terusan Sigura - gura No.7 Lowokwaru, Malang. Instansi: Universitas Negeri Malang, Malang Jawa Timur Indonesia E-mail: naufa194math@gmail.com
2019 Universitas Negeri Malang p-ISSN 2406-8780 e-ISSN 2654-7953 


\section{PENDAHULUAN}

Salah satu Teorema pertama kali ketika kita belajar matematika di Sekolah Dasar adalah Teorema Pythagoras. Teorema ini merupakan sebuah pernyataan matematis yang perlu membutuhkan bukti kebenarannya. (Jose, Parada-Daza, Miguel, \& Parada-Contzen, 2014) Pythagoras adalah seorang ahli matematika yang paling terkenal dan sosok yang berpengaruh dalam bidang matematika. Sepanjang hidupnya, ia suka bepergian ke berbagai tempat, seperti Mesir dan Babel. Pythagoras mengajarkan kepada muridnya bahwa segala sesuatu di alam semesta dapat diekspresikan dalam angka. Karena itu, Pythagoras dan para pengikutnya memuja angka dan rasio yang dapat diungkapkan oleh angka-angka ini. Teorema Pythagoras menunjukkan bahwa kuadrat sisi miring dari segitiga siku-siku sama dengan jumlah kuadrat dari panjang kedua sisi lainnya masing-masing. $\boldsymbol{a}^{\mathbf{2}}+\boldsymbol{b}^{\mathbf{2}}=\boldsymbol{c}^{\mathbf{2}}$ dimana nilai c menggambarkan panjang sisi miring, a dan $b$ panjang dari dua sisi segitiga lainnya. Teorema yang mudah dihafal bagi kebanyakan orang. Teorema dasar yang sederhana, menarik dan sangat berguna untuk dipelajari.

Bukti Teorema Pythagoras sangat bervariasi. (Bogomolny, 2016) Ada berbagai cara untuk membuktikan teorema Pythagoras dari skema pembuktian euclid. Pada era digital ini pembuktian dapat menggunaan teknologi yaitu dengan kemampuan komputer. Penggunaan komputer telah diterapkan untuk pembelajaran seperti dalam penggunaan software GeoGebra. Artikel ini menyajikan ilustrasi bagaimana kita dapat menggunakan GeoGebra untuk membimbing dan proses menemukan serta membuktikan Teorema Pythagoras. Sehingga dapat membantu mereka meningkatkan pengetahuan mereka sendiri dan proses belajar yang efektif.

\section{TEOREMA PYTHAGORAS}

Teorema Pythagoras berkaitan erat pelajaran bangun datar yaitu sebuah bangun segitiga siku - siku. Pada segitiga siku - siku dimana sisi a, sisi b merupakan panjang dari alas dan tinggi segitiga dan sisi c merupakan sebuah panjang sisi miring, maka panjang dari sisi alas segitiga ditambah panjang sisi tinggi segitiga yang keduanya dikuadrat dan dijumlah merupakan panjang dari sisi miring sebuah segitiga siku - siku. Hubungan ini dirumuskan dengan $a^{2}+b^{2}=c^{2}$. Perhatikan pada gambar dibawah ini.

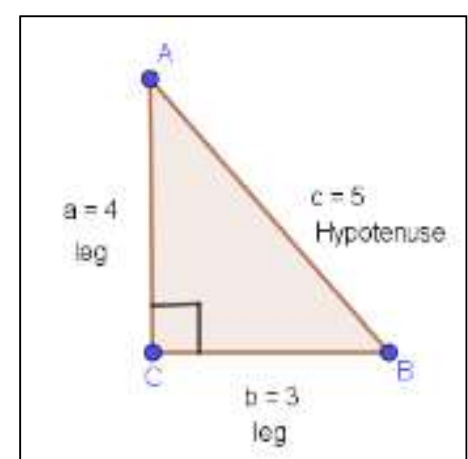

Gambar 1 : Segitiga Siku - Siku ABC

Jawab: :

$$
\begin{aligned}
& a^{2}+b^{2}=c^{2} \\
& (4)^{2}+(3)^{2}=(5)^{2} \\
& 16+9=25
\end{aligned}
$$

Teorema ini hanya berlaku untuk segitiga siku - siku. Dimana jumlah kuadrat dari panjang kedua sisi $a$ dan $b$ adalah sama dengan kuadrat dari sisi miring c. Seperti yang pada penerapn dikehidupan sehari - hari oleh (Carasco, 2016) John pulang dari sekolah, Dia berjalan 6 blok ke utara dan kemudian 8 blok ke barat. Seberapa jauh jarak john pulang dari sekolah? Bentuk visual yang dapat dimodelkan seperti berikut.

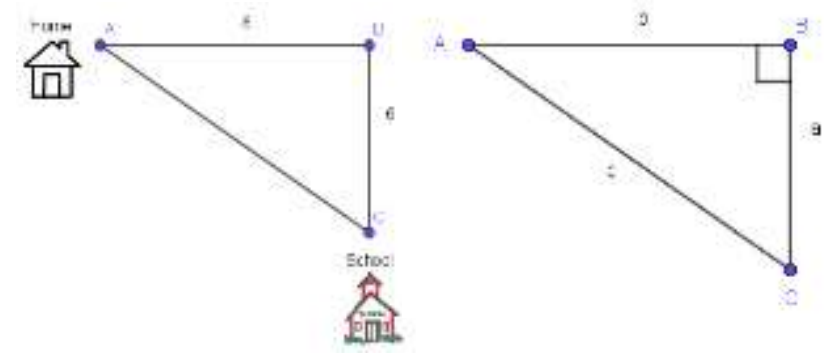

Gambar 2 :Representasi Teorema Pythagoras 
10 JINOTEP (Jurnal Inovasi dan Teknologi Pembelajaran) Kajian dan Riset dalam Teknologi Pembelajaran Vol 6, No (1), Oktober (2019), Hal. 8-14

Answer:

$$
\begin{aligned}
& c^{2}=a^{2}+b^{2} \\
& c^{2}=6^{2}+8^{2} \\
& c^{2}=36+64 \\
& c=\sqrt{100} \\
& c=10
\end{aligned}
$$

\section{jarak sekolah ke rumah adalah 10 blok}

Penerapan Teorema Pythagoras dikehidupan sehari - hari merupakan hasil dari sebuah kebenaran dalam permbuktian teorema dan penalaran murni Pythagoras. Teorema ini juga membuat banyak orang ingin membuktikan kebenarannya melaui pendekatan dan penemuan. Pada geometri Euclid Teorema Pythagoras inilah yang memiliki banyak pembuktian. (Swaminathan, 2014) dalam penelitiannya ada sekitar 500 bukti yang berbeda yang telah dinyatakan oleh Euclid. Selain bukti secara aljabar maupun dengan pendekatan geometri secara tertulis bahkan perkembangan zaman diera digital juga dapat dibuktikan secara visual dengan menggunakan teknologi yaitu memanfaatkan progam aplikasi GeoGebra.

\section{TEKNOLOGI PEMBELAJARAN MATEMATIKA}

Teknologi dalam pembelajaran merupakan sumber belajar yang penting bagi siswa dalam proses pembelajaran khususnya pembelajaran matematika. Pentingnya menggunakan teknologi dalam pengajaran matematika telah didukung oleh Dewan Nasional Guru Matematika (NCTM, 2000) Teknologi merupakan komponen yang penting dalam lingkungan belajar. Salah satunya adalah GeoGebra yang merupakan program komputer yang digunakan dalam pembelajaran matematika seperti geometri, statistik, aljabar, kalkulus. mulai dari sekolah dasar hingga universitas. M. Hohenwarter menciptakan perangkat lunak GeoGebra pada tahun 2002 untuk tujuan belajar dan mengajar matematika.
(Chrysanthou, 2008) Kualitas alat dari progam GeoGebra adalah:

- Perangkat lunak sumber terbuka dapat di akses melalui www.geogebra.org

- Memiliki pemilihan bahasa lebih dari 50 bahasa.

- Cocok untuk digunakan untuk pembelajaran matematika di berbagai umur yang berbeda.

- Memungkinan penggunan interaktif

- Memiliki tools untuk menambahkan animasi, teks dinamis dan dapat bekerja mode online / offline

- Kompatibel dengan perangkat keras (aplikasi tablet GeoGebra, iphone, ipad, android, aplikasi google play, windows 8 atau 10) dan teknologi perangkat lunak (aplikasi GeoGebra chrom, aplikasi web GeoGebra)

- Dapat diinstal diberbagai platform seperti Windows, Linux, Mac, Ubuntu \& Debian, Fedora, open SUSE, UNIX, dan XO

- Memiliki kemampuan untuk berbagi materi dan koneksi dengan orang lain di ruang online menggunakan GeoGebraTube.

Sebagai media pembelajaran matematika GeoGebra dapat memvisualisasikan konsep matematika serta membangun konsep secara matematis. (Hohenwarter \& Preiner, 2007) juga terdapat sumber belajar terbuka di sekitar perangkat lunak matematika dinamis GeoGebra di mana pendidik dapat bergabung dengan komunitas online untuk membuat dan memodifikasi mathlets. Semua materi di lingkungan GeoGebra ini tunduk pada lisensi Creative Commons yang memungkinkan setiap orang untuk membuat karya yang disesuaikan untuk tujuan non-komersial.

Pada percobaan yang dilakukan (Anabousy, 2015) pengunaan geogebra sebagai media pembelajaran dapat mengkonsolidasi atau memperkuat konsep secara terstruktur serta meningkatkan kepercayaan diri siswa dalam mengkonstruksi ketika belajar materi teorema pyhtagoras.

\section{PEMBUKTIAN TEOREMA PYTHAGORAS BERBASIS VISUAL}

Pembuktian Teorema Pythagoras ini berdasarkan skema pembuktian dari Euclid yang telah dikembangkan dan didesain dengan 
penggunaan progam geogebra yang memungkinkan adanya animasi bergerak. Berikut langkah - langkahnya.

1. Bangun sebuah segitiga siku - siku dan bentuk 3 bangun pada setiap sisinya.

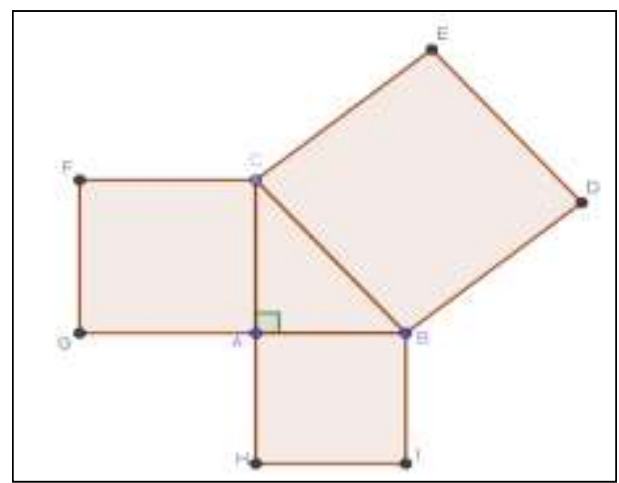

Gambar 3: Segitiga siku - siku dengan 3 bangun pada setiap sisinya

Segitiga siku - siku $A B C$, sisi $A B$ adalah alas segitiga, sisi $\mathrm{AC}$ adalah tinggi segitiga dan sisi $\mathrm{BC}$ adalah sisi miring segitiga dan bentuk 3 bangun pada setiap sisi segitiga siku - siku. Bangun persegi HIBA terletak pada sisi AB (alas). Bangun persegi GACF terletak pada sisi AC (tinggi). Bangun persegi $\mathrm{BDEC}$ terletak pada sisi BC (sisi miring)

2. Bentuk sebuah Garis Paralel pada tools GeoGebra lalu buat perpotongan dua garis.

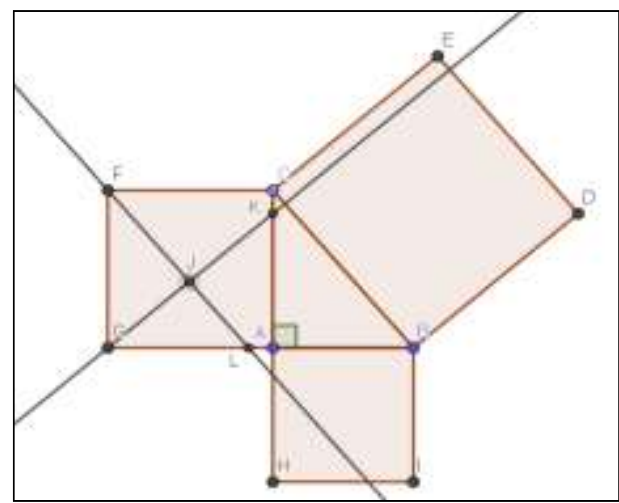

Gambar 4 : Dua Garis Berpotongan di dalam persegi GACF.

Pada persegi GACF dibuat perpotongan dua garis dan buat titik $\mathrm{L}$ pada sisi AG dan titik K pada sisi AC dan titik $\mathrm{J}$ sebagai titik perpotongan yang terletak di dalam persegi GACF kemudian sembunyikan dua garis dengan menghilangkan centang pada tampilan aljabar di GeoGebranya.

3. Bangun sebuah poligon dan berikan warna yang berbeda setiap poligon yang dibuat.

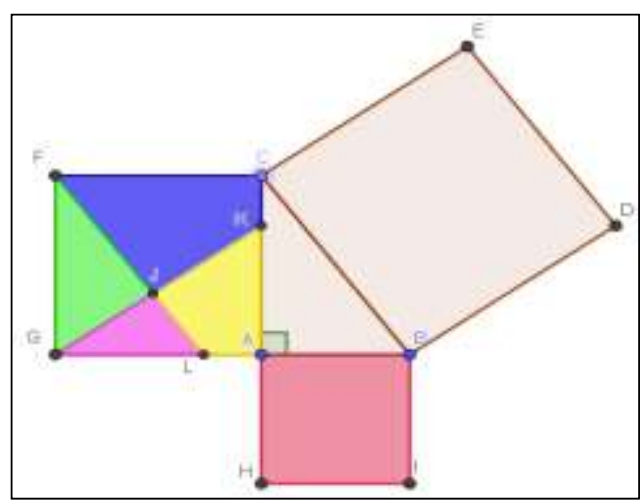

Gambar 5: Warna yang berbeda pada setiap poligon

Tebentuk 4 poligon didalam persegi GACF. Poligon yang tebentuk adalah FJKC, FJG, GJL, dan JKAL. Kemudian masing-masing poligon memiliki warna yang berbeda termasuk persegi HIBA.

4. Buat sebuah lingkaran dengan titik pusat di D dengan panjang jari - jari sama dengan garis FJ.

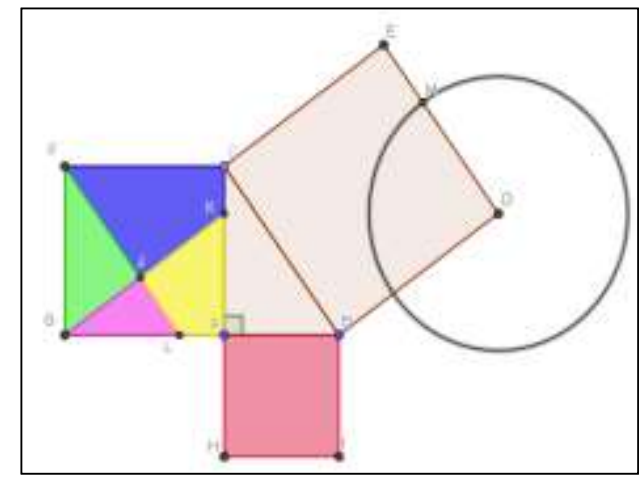

Gambar 6: Lingkaran dengan titik pusat di D

Pilih icon jangka yang terdapat pada toolbox GeoGebra dan bentuk sebuah lingkaran dengan titik pusat $\mathrm{F}$ dengan jari jari FJ lalu pindahkan ke titik D sebagai titik pusat lingkaran. Lalu buat titik perpotongan antara sisi DE dengan keliling lingkaran dan terbentuk titik $\mathrm{M}$. 
12 JINOTEP (Jurnal Inovasi dan Teknologi Pembelajaran) Kajian dan Riset dalam Teknologi Pembelajaran Vol 6, No (1), Oktober (2019), Hal. 8-14

5. Buat slider dan masukkan input $\operatorname{Min}=0, \operatorname{Max}=1$, Increment $=0.01$, Speed $=3$ pada Increasing

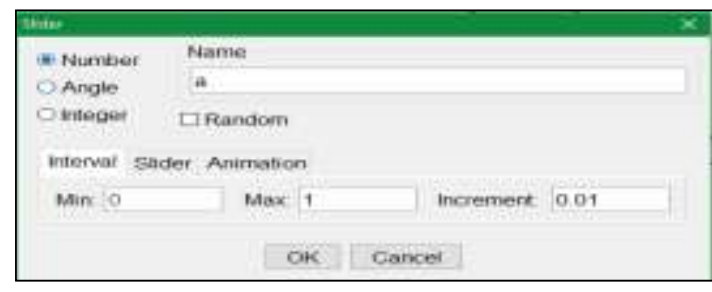

Gambar 7 : Tampilan Slider

6. Buat vector dengan memaskukan pada input Bar enters setiap vector and Translatsikan.

- $\mathrm{u}=\mathrm{a} * \operatorname{Vector}(\mathrm{J}, \mathrm{E})$

- $\mathrm{v}=\mathrm{a} * \operatorname{Vector}(\mathrm{J}, \mathrm{D})$

- $\mathrm{v}=\mathrm{a} * \operatorname{Vector}(\mathrm{J}, \mathrm{B})$

- $\mathrm{tt}=\mathrm{a} * \operatorname{Vector}(\mathrm{J}, \mathrm{C})$

- $\mathrm{rr}=\mathrm{a} * \operatorname{Vector}(\mathrm{B}, \mathrm{M})$

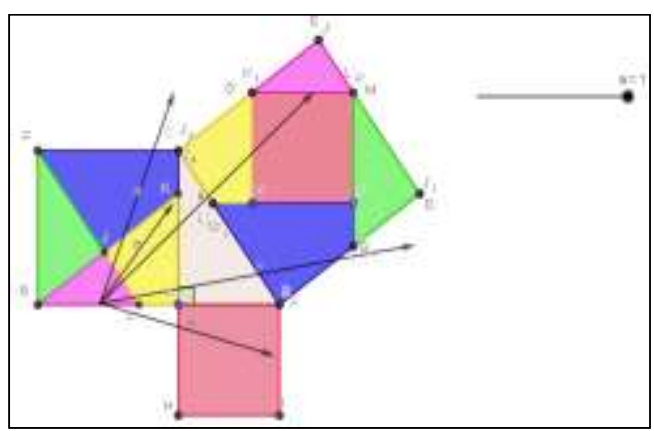

Gambar 8 : Translasi setiap polygon dengan vector

Setiap masukan pada input bar memvisualisasikan garis lurus ke arah kanan. Pilih ikon translasi objek oleh vektor pada toolbox GeoGebra kemudian translasi poligon oleh vector sampai mengarah ke persegi BDEC. Setiap poligon mentranslasikan ke arah persegi BDEC.

7. Sembunyikan semua vektor dan titik setelah memindahkan dan penggunaan slider sebagai animasi pergerakan bukti secara visual Teorema Pythagoras. Pembuktian dengan menggerakan slider ke kanan dari angka 0 sampai 1 .

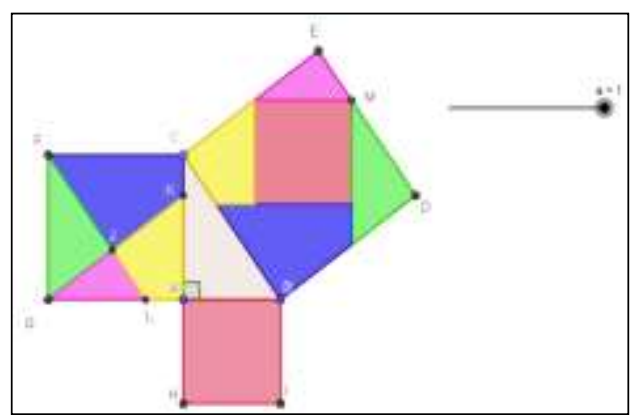

Gambar 9 : pergerakan slider ke angka 1

Mentranslasikan bangun persegi HIBA dan persegi GACF yang mana terdapat beberapa 4 poligon JKCF, JLAK, GLJ, GJF dengan menggerakan slider ke arah kanan $\mathrm{a}=1$. (Mathematic94, 2018) Progam geogebra dapat membutikan secara visual teorema pythagoras bahwa penjumlahan dari sebuah bentuk persegi dan jumlah poligon memiliki jumlah ukuran yang sama pada persegi BDEC.

\section{HASIL DAN PEMBAHASAN}

(Bogomolny, 2016) Secara aljabar, bukti Teorema Pythagoras menggunakan skema dari Euclid seperti ini.

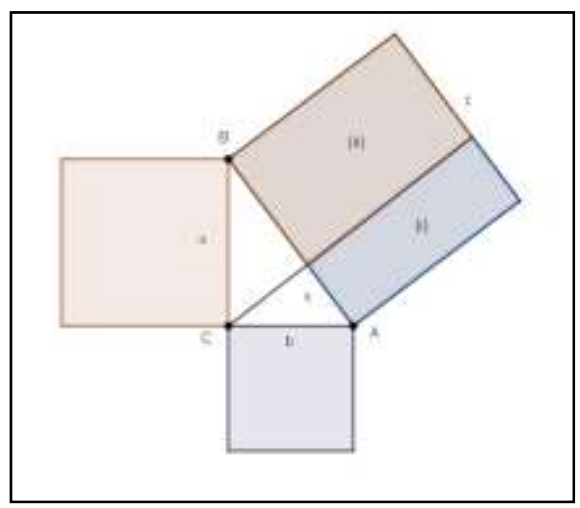

Gambar 10 : Skema dari Euclid

Berdasarkan bentuk sebuah kesebangunan segitiga diperoleh nilai $\frac{x}{b}=$ $\frac{b}{c}$ sehingga diperoleh nilai $x=\frac{b^{2}}{c}$ maka luas dari (i) $=x \cdot c=\frac{b^{2}}{c} \cdot c=b^{2}$ dengan cara yang sama luas dari (ii) $=a^{2}$ sehingga diperoleh hasil $a^{2}+b^{2}=$ luas (i) + luas (ii) $=c^{2}$

Pada Geometri klasik (Rosero, 2016) pembuktian Teorema Pythagoras menawarkan rumus luas suatu bangun yang berhubungan dengan segitiga dimana semua 
pengukuran sudutnya diketahui tetapi hanya pengukuran satu sisi saja yang diketahui.

Dengan menggunakan geogebra dapat dilakukan menggunakan prinsip kesamaan luas bangun, sehingga menunjukan pergeseran bayangan seperti pada gambar 11.

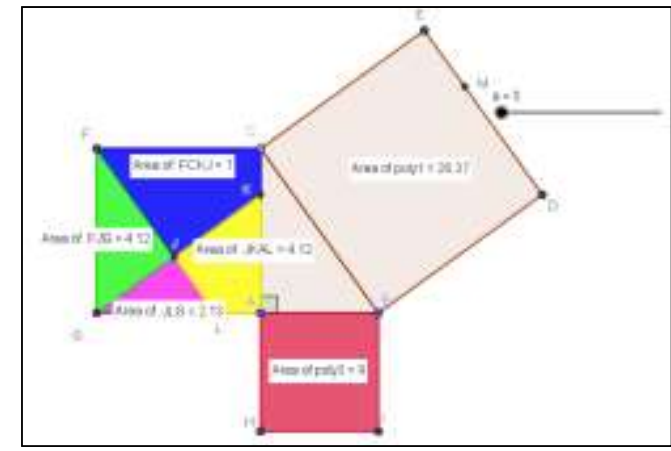

Gambar 11 : Ukuran luas tiap poligon

Pada gambar 11, menunjukan bahwa perubahan bentuk bangun datar karena strain atau peregangan dan translasi yang sama sama tidak mengubah ukuran luas bangun datar tersebut.

Perubahan yang bergerak merupakan strain dan translasi. sebab pada Transformasi strain, translasi, dan refleksi itu tidak mengubah luas bangun datar. Luas bangun $\mathrm{BDEC}=26.37$ dimana ini merupakan bagian dari sisi miring. Penjumlahan daripada bangun HIBA + $\mathrm{JKCF}+\mathrm{LAKJ}+\mathrm{GLJ}+\mathrm{GJF}=26.37$

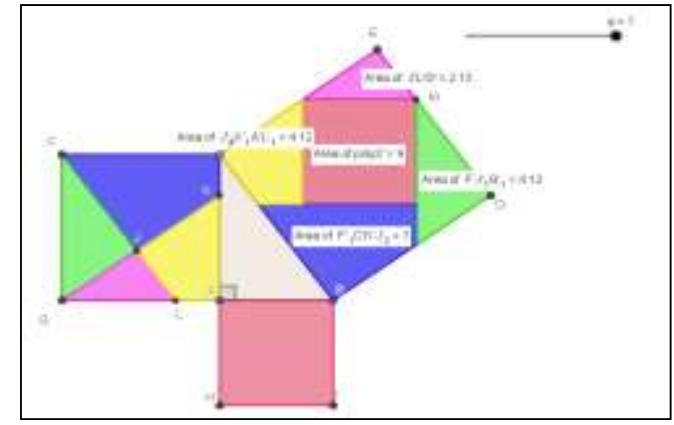

Gambar 12 : Translasi pada persegi BDEC

Ini adalah salah satu bukti dalam membuktikan kebenaran Teorema Pythagoras, dengan penggunaan GeoGebra. Siswa dapat menjelajahi objek geometris secara visual dan dinamis untuk menghasilkan temuan mereka.

(Tuan Minh Pham, 2012) Fitur yang terdapat pada GeoGebra dapat dengan mudah dijalankannya secara dinamis pengguna dengan mudah dapat menemukan titik, garis yang sesuai dengan konfigurasi mereka dengan memilih objek pada toolbox dan pengguna dapat menarik dan melepaskan objek ini untuk menerapkan aturan sesuai intruksi. Sependapat dengan dalam penelitian yang dilakukan (Carević1 \& Denić2, 2017) Bahwa siswa telah membuat karya yang telah mereka kerjakan dan hasil dari visualisasi tentang prinsip prinsip matematika membuat siswa lebih jelas memahaminya. Hubungan representasi visual membuat siswa lebih mudah mengingatnya serta lebih efektif dalam menguasai bentuk rumus matematika.

Hasil dari sebuah pembuktian memiliki kemampuan untuk menghasilkan visualisasi dari output objek geometris dengan cepat dan akurat. Sesuai (Contreras, 2014) GeoGebra membimbing peserta didik untuk menemukan dan memperluas salah satu teorema yang paling indah dan elegan. GeoGebra akan membantu siswa untuk mengeksplorasi konsep lebih detail dan membantu mereka membangun dan mengembangkan pengetahuan mereka.

\section{KESIMPULAN}

Artikel ini, menggambarkan bagaimana kita menggunakan teknologi sebagai sumber belajar dalam proses pembelajaran sebagaimana yang telah dibuktikan tentang kebenaran sebuah Teorema Pythagoras dengan program GeoGebra. Selain itu, siswa dan guru dapat mengetahui fungsi sekaligus kegunaan dan tools yang terdapat pada program GeoGebra. Dengan menerapkan progam GeoGebra sebagai media dalam proses pembelajaran matematika akan melatih keterampilan mereka yang dapat meningkatkan pemahaman yan mereka temukan sendiri.

Penelitian yang telah dilakukan (Majerek1, 2014) progam GeoGebra dapat membantu dalam mengajar matematika, serta digunakan untuk pengajaran yang aktif dan berorientasi pada masalah dan menumbuhkan eksperimen dan penemuan baik di ruang kelas maupun di rumah. sekaligus membangun konsep, menyelesaikan, dan memberikan 
14 JINOTEP (Jurnal Inovasi dan Teknologi Pembelajaran) Kajian dan Riset dalam Teknologi Pembelajaran Vol 6, No (1), Oktober (2019), Hal. 8-14

gambaran setiap masalah yang terdapat dimatematika.

Saya mengajak para pembaca untuk mencoba program GeoGebra sehingga dapat memfasilitasi para pembaca untuk belajar matematika dan memahami konsep matematika dengan mudah. Dengan melakukan latihan dengan GeoGebra, para pembaca diharapkan mendapatkan sudut pandang dan paradigma baru tentang matematika khususnya bukti Teorema Pythagoras.

\section{DAFTAR RUJUKAN}

Anabousy, A. \&. (2015). Constructing and consolidating mathematical knowledge in the geogebra environment by a pair of students. Psychology of Mathematics Education, (PME-39).

Bogomolny, A. (2016). Cut The Knot. (A. Powell, Producer, \& University of Chicago Press, 1995) Retrieved July 2018, from Interactive Mathematics Miscellany: http://www.cutthe-knot.org/pythagoras/

Carasco, J. (2016). Basic-Mathematics. Retrieved July 2018, from Basic Mathematics Skills: https://www.basicmathematics.com/pythagorean-theoremword-problems.html

Carević1, M. M., \& Denić2, D. N. (2017, October). Geogebra To Help In The Understanding And Memorizing. Serbia: Science and Higher Education in Function of Sustainable Development.

Chrysanthou, I. (2008, July 14). The Use Of Ict In Primary Mathematics In Cyprus: The Case Of Geogebra. International Perspectives In Mathematics Education.

Contreras, J. N. (2014). Discovering and Extending Viviani's Theorem with GeoGebra. (V. ANTOHE, Ed.) GeoGebra International Journal of Romania, Vol. 3 No.1.

Hohenwarter, M., \& Preiner, J. (2007). Creating Mathlets with Open Source Tools. The Journal of Online Mathematics and Its Applications, 7, Article ID 1574.

Jose, R., Parada-Daza, Miguel, I., \& Parada-Contzen. (2014). Pythagoras and The Creation of Knowledge. Open Journal of Philosophy, 4, 68-74.

doi:http://dx.doi.org/10.4236/ojpp.2014.410 10
Majerek1, D. (2014). APPLICATION OF

GEOGEBRA FOR TEACHING

MATHEMATICS. Advances in Science and Technology Research Journal, 8, 51-54. doi:10.12913/22998624/567

Mathematic94, N. (2018, August ). Pythagorean Theorem. Retrieved from www.geogebra.org: https://www.geogebra.org/material/show/id/ sukabedj

May, V., \& Courtney, S. (2016, February). Developing Meaning in Trigonometry. Illinois Mathematics Teacher, Vol 63, No 1. Retrieved from journal.ictm.org/index.php/imt/article/down load/102/91

NCTM. (2000). Principles and Standards for School Mathematics. Reston: National Council of Teachers of Mathematics.

Rosero, C. J. (2016). Euclidean And Napoleonian Theorems : Their Derivation From Pythagorean. International Journal of Current Research, 8(3). Retrieved from http://www.journalcra.com

Swaminathan, S. (2014). The Pythagorean Theorem. Journal of Biodiversity, Bioprospecting, 1(3), 1. doi:10.4172/2376-0214.1000128

Tuan Minh Pham, Y. B. (2012). A Combination of a Dynamic Geometry Software With a Proof Assistant for Interactive Formal Proofs. Electronic Notes in Theoretical Computer Science 285 (2012) 43-55, 1571-0661. doi:10.1016/j.entcs.2012.06.005 